\title{
Extended spectrum-beta-lactamase producing Enterobacteriaceae causing nosocomial infection in a tertiary care hospital, Nepal
}

MK Sah

From 3rd International Conference on Prevention and Infection Control (ICPIC 2015)

Geneva, Switzerland. 16-19 June 2015

\section{Introduction}

The emergence and spread of resistance in Enterobacteriaceae are complicating the treatment of serious nosocomial infections and threatening to create species resistant to most currently available antimicrobial agents. Extended spectrum $\beta$-lactamase (ESBL)-producing Enterobacteriaceae causing nosocomial infection pose unique challenges to clinical microbiologists, clinicians, infection control professionals and antibacterialdiscovery scientists in Nepal.

\section{Objectives}

The study was aimed to determine the ESBL-producing Enterobacteriaceae accountable for nosocomial infection.

\section{Methods}

The study was conducted at Tribhuvan University Teaching Hospital (TUTH), a 750 bedded tertiary care referral hospital located at Kathmandu, Nepal. A total of one hundred fifty nine bacterial isolates causing nosocomial infection were studied over a period of one year from March 2011 to February 2012 as described by American Society for Microbiology (ASM). Antibiotic susceptibility testing was performed by the Kirby-Bauer Disk Diffusion technique as recommended by Clinical and Laboratory Standards Institute (CLSI). A combination disk method was done for the detection of ESBL-producing isolates according to the guidelines of CLSI. Data were analyzed using SPSS 17.0 software and interpreted according to frequency distribution and percentage.

\section{Results}

Escherichia coli $61.6 \%(\mathrm{n}=98)$ was found to more predominant which was followed by Klebsiella pneumoniae 31.4\% ( $\mathrm{n}=50)$, Citrobacter freundii 5.7\% ( $\mathrm{n}=9)$, and Morganella morgannii $1.3 \%(\mathrm{n}=2)$. The prevalence of ESBL was $23.9 \%(n=38)$. Among the ESBL producer Klebsiella pneumoniae was found to be predominant $26 \%(\mathrm{n}=13)$ which was followed by E.coli $24.5 \%(\mathrm{n}=24)$ and C. freundii $12.5 \%(\mathrm{n}=1)$.

\section{Conclusion}

It is clear that high prevalence of bacterial strains producing ESBL in our hospital which prompts a special attention for the management of such patients as well as urgent need for implementation of infection control strategies to prevent the dissemination of such strains. ESBL detection should be routinely performed in clinical laboratory as false reporting would results in treatment failure despite in vitro sensitivity.

\section{Disclosure of interest}

None declared.

Published: 16 June 2015

doi:10.1186/2047-2994-4-S1-P122

Cite this article as: Sah: Extended spectrum-beta-lactamase producing

Enterobacteriaceae causing nosocomial infection in a tertiary care hospital, Nepal. Antimicrobial Resistance and Infection Control 2015

4(Suppl 1):P122. 